\title{
Inhaltsverzeichnis Band 9: Flachdach
}

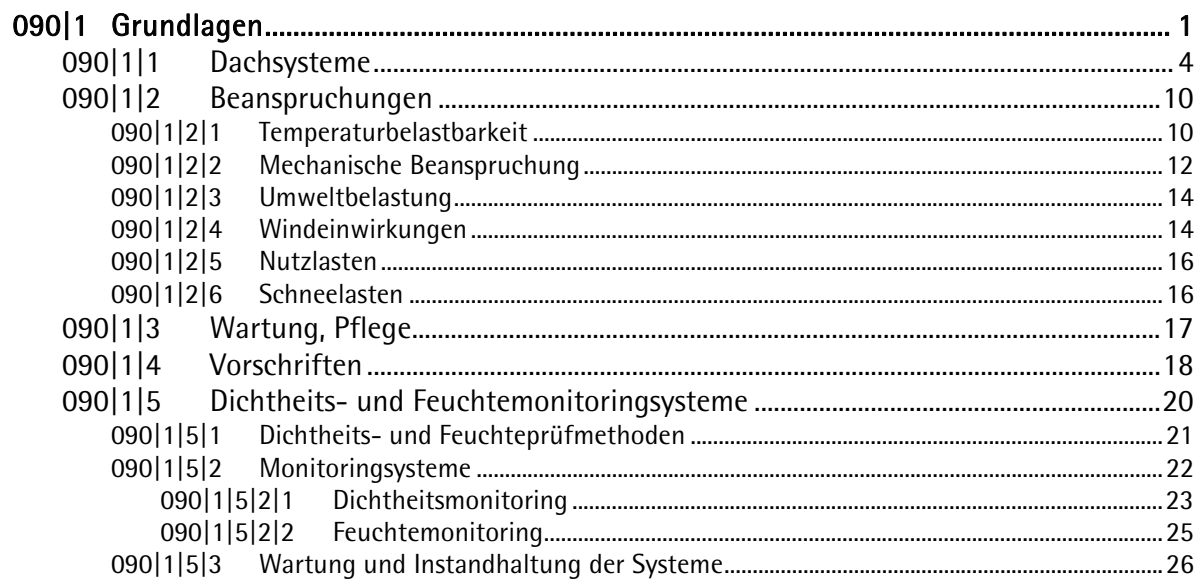

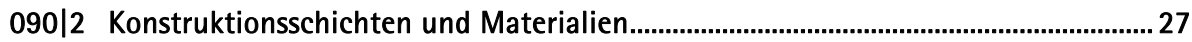

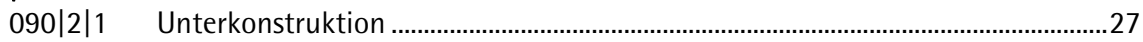

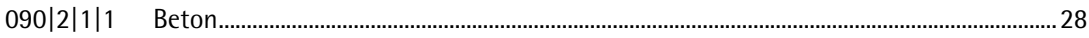

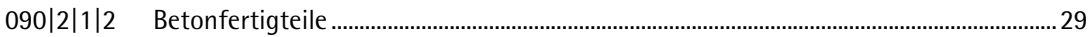

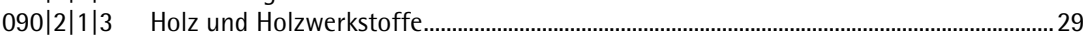

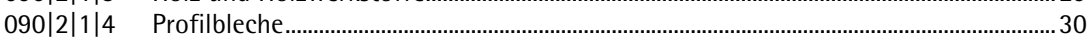

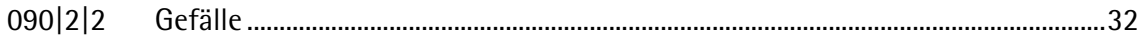

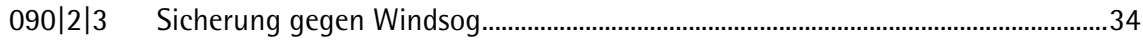

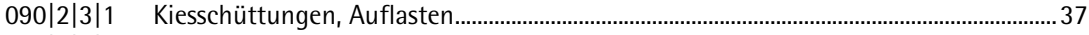

$090|2| 3 \mid 2 \quad$ Mechanische Befestigungen ..............................................................................................

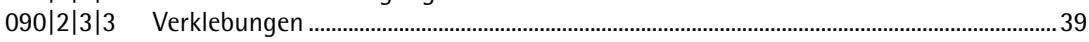

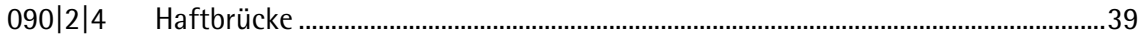

$090|2| 4 \mid 1 \quad$ Lösungsmittelhaltige Voranstriche ………………………………………………………..... 40

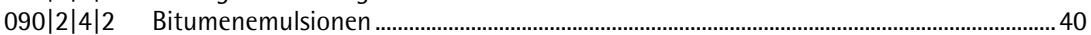

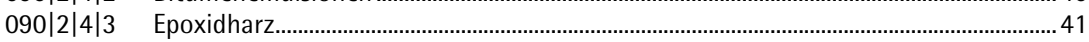

090|2|5 Trenn- und Ausgleichsschichten................................................................................. 41

090|2|6 Dampfbremsen, Dampfsperren ............................................................................ 43

090|2|7 Wärmedämmung........................................................................................................4

$090|2| 7 \mid 1 \quad$ Polystyrol-, Polyurethan-Hartschäume.................................................................................. 48

$090|2| 7 \mid 2 \quad$ Mineralfaser, Mineralwolle........................................................................................................51

$090|2| 7 \mid 3 \quad$ Holzfaser, Holzwolle ............................................................................................................ 52

$090|2| 7 \mid 4 \quad$ Korkdämmstoffe ……………………………………................................................................. 53

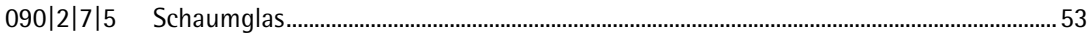

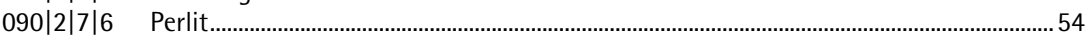

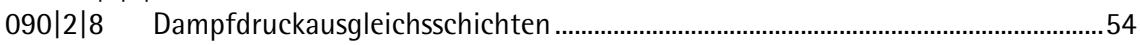

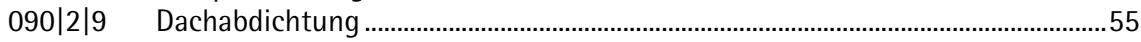

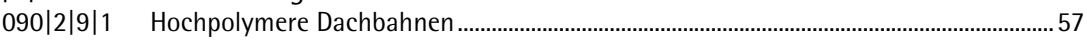

$090|2| 9 \mid 2 \quad$ Flüssigkunststoffe............................................................................................................... 59

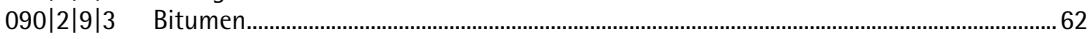

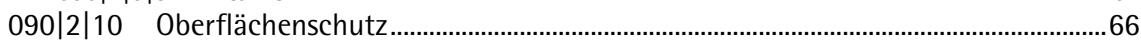

$090|2| 10 \mid 1 \quad$ Schwerer Oberflächenschutz ...................................................................................................66

090|2|10|2 Leichter Oberflächenschutz......................................................................................................6

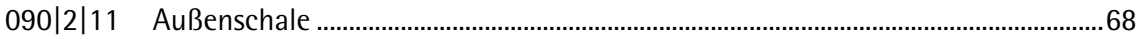

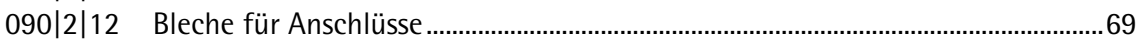

090|2|13 Bauschutzabdichtung ........................................................................................... 


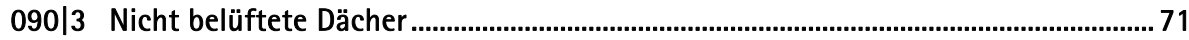

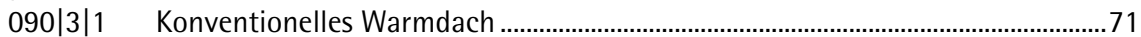

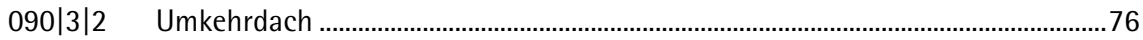

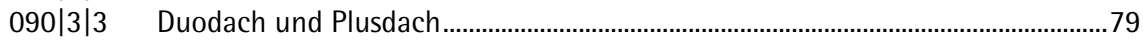

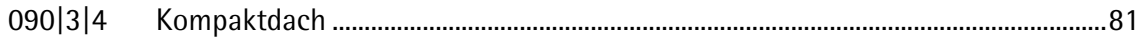

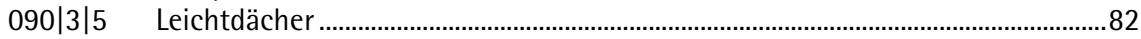

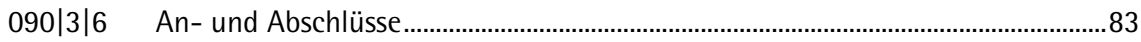

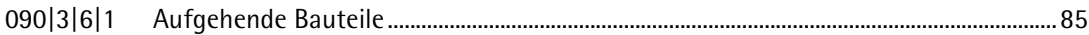

$090|3| 6 \mid 2$ Attika - Dachrand ohne Überstand ……………..............................................................90

$090|3| 6 \mid 3 \quad$ Dachrand mit Überstand ……………………….........................................................................93

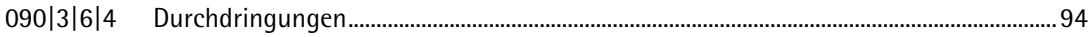

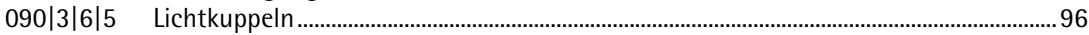

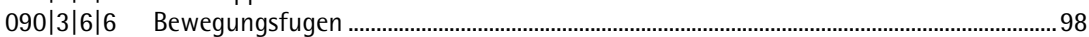

090|3|6|7 Absturzsicherungen ........................................................................................................101

090|3|7 Verarbeitung und Herstellung............................................................................ 103

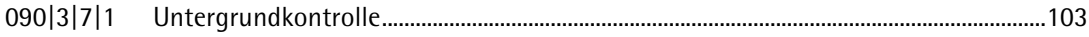

090|3|7|2 Voranstrich und Grundierung.......................................................................................

090|3|7|3 Diffusionshemmende Schichten ..................................................................................105

$090|3| 7 \mid 4 \quad$ Wärmedämmung ................................................................................................................

090|3|7|5 Dachabdichtung ………………………………………………………………………………106

$090|3| 7|5| 1 \quad$ Polymerbitumenbahnen ………………………....................................................107

090|3|7|5|2 Elastomere Kunststoffdichtungsbahnen (EPDM) .................................................108

$090|3| 7|5| 3 \quad$ Thermoplastische Kunststoffdichtungsbahnen .....................................................108

$090|3| 7|5| 4 \quad$ Flüssigabdichtungen ..............................................................................................109

090|3|7|6 Ausgleichs-, Schutz-, Gleit- und Trennschichten ............................................................110

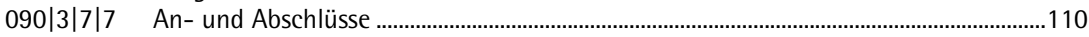

090|3|7|8 Beschüttungen und schwerer Oberflächenschutz...........................................................111

090|3|7|9 Zubehör und Einbauteile............................................................................................................111

$090|3| 7 \mid 10$ Sanierungen ............................................................................................................................... 112

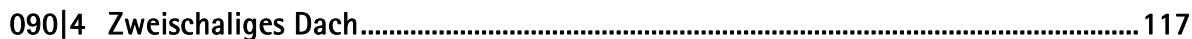

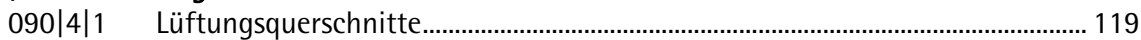

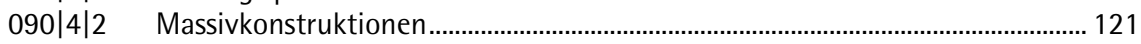

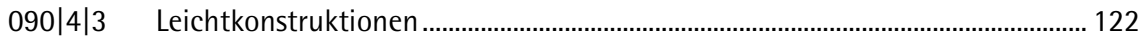

090|4|4 An- und Abschlüsse....................................................................................... 124

090|4|4|1 Aufgehende Bauteile ........................................................................................................124

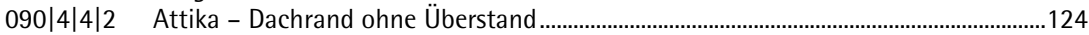

090|4|4|3 Dachrand mit Überstand ......................................................................................................125

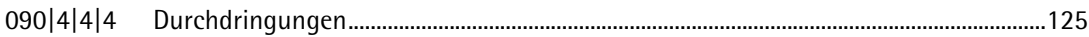

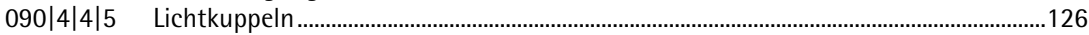

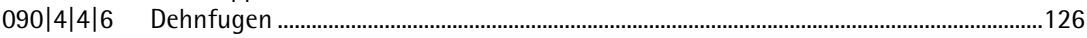

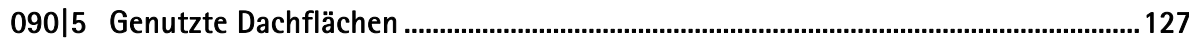

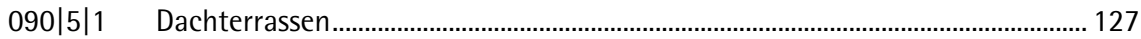

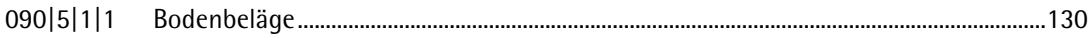

090|5|1|2 An- und Abschlüsse Terrassen .......................................................................................134

090|5|1|3 Türschwellen ............................................................................................................................137

090|5|2 Dachbegrünungen .......................................................................................... 141

090|5|2|1 Begrünungsarten ...............................................................................................................

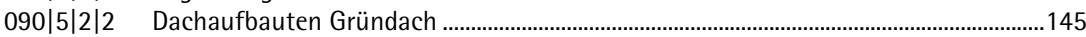

090|5|2|3 An- und Abschlüsse begrünte Dächer ..................................................................................150

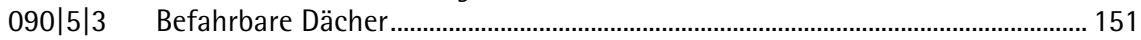

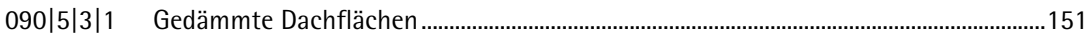

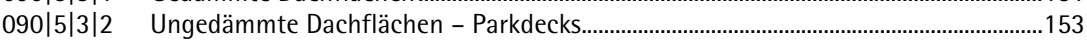

090|5|4 Dachflächen mit Solar- und Photovoltaikanlagen ................................................ 155

090|5|5 Retentionsdächer ................................................................................................... 156 


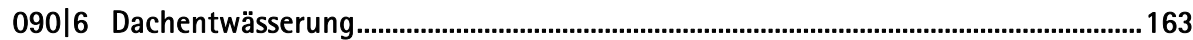

090|6|1 Bemessung Dachentwässerung ……………………………………..................... 163

090|6|1|1 Bemessungsniederschläge ……………………………………………………………....164

090|6|1|2 Abflussbeiwert .....................................................................................................................165

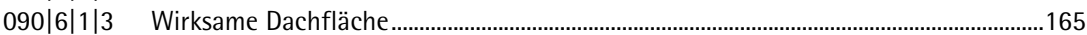

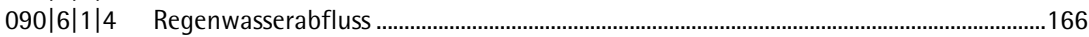

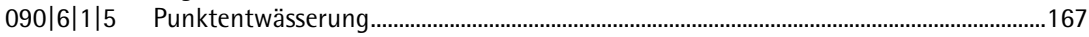

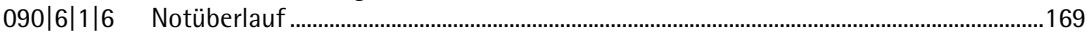

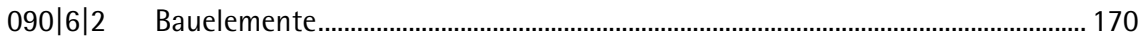

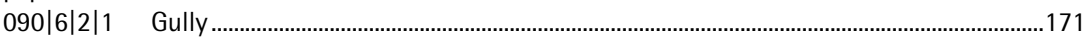

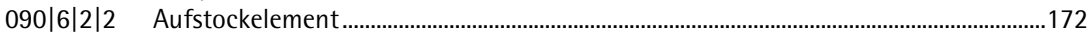

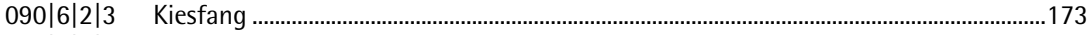

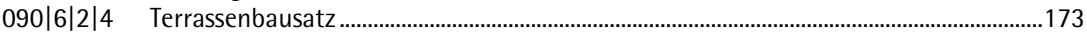

090|6|2|5 Entwässerungsrinnen.....................................................................................................174

090|6|2|6 Gründachzubehör ........................................................................................................174

090|6|2|7 Geruchsverschluss..........................................................................................................175

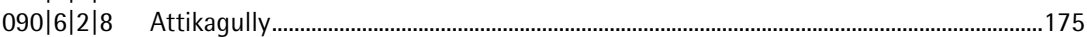

090|6|3 Detailausbildungen Warmdach............................................................................ 176

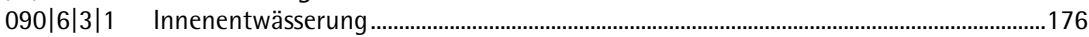

090|6|3|2 Außenentwässerung ………………………………………………………………….....177

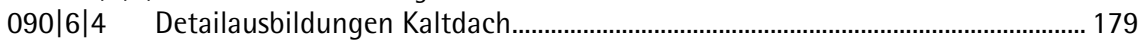

090|6|4|1 Innenentwässerung ........................................................................................................179

090|6|4|2 Außenentwässerung ............................................................................................................179

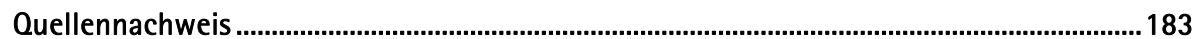

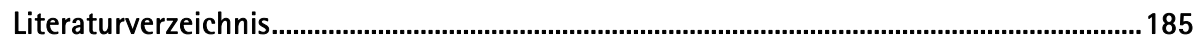

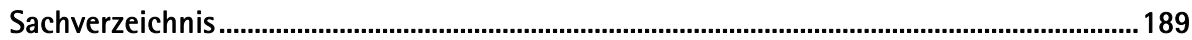

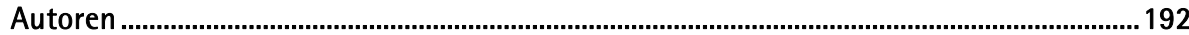


